1 Spitzer R, Williams J, Gibbon M, First M. Structured clinical interview for DSM III-R (SCID-P, version 1.0). Washington DC: American Psychiatric Press, 1990.

2 Brown G, Harris T. Social origins of depression: a study of psychiatric disorder in women. London: Tavistock, 1978

3 Dean C. Psychiatric morbidity following mastectomy: preoperative predictors and types of illness. J Psychosom Res 1987;31:3, 385-92.

4 Fallowfield L, Hall A, Maguire G, Baum M. Psychological outcomes of different treatment policies in women with early breast cancer outside a clinical trial. BMJ 1990;301:575-80

5 Ramirez A, Richards M, Jarrett S, Fentiman I. Can mood disorder in women with breast cancer be identified preoperatively? $\mathrm{Br} J$ Cancer 1995;72:1509-12.

6 Chochinov HM, Wilson KG, Enns M, Lander S. Prevalence of depression in the terminally ill: effects of diagnostic criteria and symptom threshold judgments. Am J Psychiatry 1994;151:537-40.

7 Harrison J, Maguire P. Predictors of psychiatric morbidity in cancer patients. Br J Psychiatry 1994;165:593-8.
8 Pinder KL, Ramirez AJ, Richards MA, Gregory WM. Cognitive responses and psychiatric disorder in women with operable breast cancer Psycho-Oncology 1994:3:129-37.

9 Fallowfield L. Effects of breast conservation on psychological morbidity associated with diagnosis and treatment of early breast cancer. BMJ 1986;293:1331-4.

10 Fallowfield LJ, Hall A, Maguire P, Baum M, A'Hern RP. Psychological effects of being offered choice of surgery for breast cancer. BMJ $1994 ; 309: 448$

11 Burgess C, Ramirez A, Richards M, Potts HWW. Does the method of detection of breast cancer affect subsequent psychiatric morbidity? Eur J Cancer 2002;38:1622-5.

12 Haddad P, Maguire P, Jones B. Effect of mode of breast cancer diagnosis on subsequent affective disorder. Breast 1994:3:218-21.

13 National Institute for Clinical Excellence. Supportive and palliative care for people with cancer. London: NICE, 2004

(Accepted 20 December 2004)

doi 10.1136/bmj.38343.670868.D3

\title{
Insulin resistance and depressive symptoms in middle aged men: findings from the Caerphilly prospective cohort study
}

Debbie A Lawlor, Yoav Ben-Shlomo, Shah Ebrahim, George Davey Smith, Stephen A Stansfeld, John W G Yarnell, John E J Gallacher

Insulin resistance may protect against depression, possibly through an effect on circulating free fatty acid concentrations and brain serotonin concentration, ${ }^{12}$ although a recent study contradicted these findings. ${ }^{3}$ Studies to date have either used indirect measures of insulin resistance, ${ }^{1}$ or they have been cross sectional. ${ }^{23}$ We assessed the association of insulin resistance with depressive symptoms in a prospective cohort.

\section{Participants, methods, and results}

The Caerphilly cohort study has been described in detail before. ${ }^{4}$ In phase I (1979-83), 2512 (89\% of eligible) men aged 45-59 years from Caerphilly in Wales provided fasting blood samples. Insulin resistance (homoeostasis model assessment (HOMA) score) was derived from fasting insulin and glucose. ${ }^{5}$ HOMA scores were not calculated for men with diabetes or high fasting glucose ( $\geq 7.0 \mathrm{mmol} / \mathrm{l})$.

In phases II (1984-88), III (1989-93), and IV (19937), depressive symptoms were measured by the 30 item general household questionnaire (GHQ). This was validated at phase II in a subgroup $(n=97)$ by comparison with a clinical interview schedule given by a psychiatrist blinded to the GHQ score. ${ }^{4}$ Based on receiver operating characteristics, we defined men scoring five or above as having mild to moderate psychological distress. ${ }^{4}$

At phase I, 2203 (88\%) of the men had assessment of insulin resistance or diabetes status. Of the surviving men, the numbers with GHQ data at phases II, III, and IV were 1619/2025 (80\%), 1236/1845 (67\%), and $1088 / 1675(65 \%)$.

Insulin resistance and high GHQ score were not associated at any phase of follow up (table). Diabetes at baseline was associated with a tendency to reduced odds of high GHQ at follow up, but, owing to small numbers, these estimates are imprecise. Additional adjustment for smoking, physical activity, alcohol consumption, and adult and childhood social class did not substantively alter any of the findings.

Insulin resistance and GHQ scores were not associated in linear regression models with GHQ as a continuous outcome (all $\mathrm{P}$ values $>0.2$ ). When fasting insulin was used there was no evidence of an association with GHQ. In cross sectional analyses (exposures and outcomes measured at phase II) there was no association between any HOMA scores, fasting insulin, or diabetes and GHQ score. We also found no associations between body mass index, systolic blood pressure, high density lipoprotein cholesterol, or (logged) triglyceride concentration and GHQ in either prospective or cross sectional analyses (all $\mathrm{P}$ values $>0.3)$.

\section{Comment}

Insulin resistance was not associated with reduced depressive symptoms in a prospective study of middle aged men. This contradicts our earlier findings in a cross sectional study of older women, in which there was an inverse association with both clinically diagnosed depression and use of antidepressant drugs, ${ }^{2}$ and the findings of a second cross sectional study which found a positive association between insulin resistance and depression assessed using the Beck's depression inventory. ${ }^{3}$ These contradictory findings may be due to the cross sectional nature of the earlier studies. A large prospective study, in which reverse causality would be unlikely, found that indicators of insulin sensitivity were associated with suicide risk. ${ }^{1}$ Taken together these findings indicate that insulin resistance may protect against only severe depression.

This article was posted on bmj.com on 31 January 2005: http://bmj.com/ cgi/doi/10.1136/bmj.38377.616921.F7
Department of Social Medicine, University of Bristol, Bristol BS8 2PR

Debbie A Lawlor senior lecturer in epidemiology and public health

Yoav Ben-Shlomo senior lecturer in clinical epidemiology Shah Ebrahim professor in epidemiology of ageing George Davey Smith professor of clinical epidemiology

Centre for

Psychiatry, Barts and the London, Queen Mary, University of London

Stephen A Stansfeld professor of psychiatry Department of Epidemiology and Public Health, The Queen's University of Belfast

John W G Yarnell reader in epidemiology and public health continued over 
Department of Epidemiology, Statistics and Public Health, University of Wales College of Medicine

John E J Gallacher senior lecturer in environmental epidemiology

Correspondence to: D A Lawlor d.a.lawlor@ bristol.ac.uk

Insulin resistance and diabetes at baseline (1979-83) and GHQ score (indicative of depressive symptoms) at different phases of follow up in middle aged men in the Caerphilly prospective cohort study

\begin{tabular}{|c|c|c|c|c|}
\hline & \multicolumn{3}{|c|}{ Phase of follow up } & \multirow{2}{*}{$\begin{array}{c}\text { High } \mathrm{GHQ}^{*} \text { at all three follow } \\
\text { up phases }\end{array}$} \\
\hline & II & III & IV & \\
\hline $\begin{array}{l}\text { Median no of years from } \\
\text { baseline }\end{array}$ & 5 & 10 & 14 & 14 \\
\hline No with GHQ data & 1619 & 1236 & 1088 & 944 \\
\hline No with high GHQ & 362 & 289 & 271 & 63 \\
\hline
\end{tabular}

Age and time of blood

sampling adjusted

prevalence of high GHQ

score by insulin resistance

or diabetes $(\%(95 \% \mathrm{CI}))$ :

\begin{tabular}{|c|c|c|c|c|}
\hline Lowest fourth HOMA & 22.9 (19.1 to 27.2) & 21.7 (17.4 to 26.7 ) & 24.1 (19.5 to 29.4) & 7.9 (5.1 to 12.0) \\
\hline 2nd fourth HOMA & 21.4 (17.7 to 25.7) & 22.2 (18.0 to 27.2) & 21.6 (17.0 to 27.0$)$ & 4.3 (2.4 to 7.6$)$ \\
\hline 3rd fourth HOMA & 24.6 (20.6 to 29.1$)$ & 23.7 (19.2 to 28.9) & 27.0 (21.9 to 32.7$)$ & 6.7 (4.1 to 10.7 ) \\
\hline Highest fourth HOMA & 20.5 (16.7 to 25.0) & 26.9 (22.1 to 32.4$)$ & 28.8 (23.4 to 34.9$)$ & 7.3 (4.4 to 11.9) \\
\hline $\begin{array}{l}\text { Diabetes or high fasting } \\
\text { glucose }\end{array}$ & 19.5 (11.1 to 31.9$)$ & 16.3 (7.5 to 31.8$)$ & 12.3 (4.7 to 28.5$)$ & 4.0 (0.6 to 2.3 ) \\
\hline $\begin{array}{l}\text { Age and time of sampling } \\
\text { adjusted odds ratio ( } 95 \% \\
\text { CI) per increase of one } \\
\text { quarter HOMA distribution† }\end{array}$ & 0.97 (0.87 to 1.08$)$ & 1.09 (0.96 to 1.22$)$ & 1.09 (0.96 to 1.23$)$ & 0.97 (0.77 to 1.23$)$ \\
\hline $\begin{array}{l}\text { Age and time of sampling } \\
\text { adjusted odds ratio (95\% } \\
\text { Cl) comparing those with } \\
\text { diabetes or high glucose to } \\
\text { those withoutł }\end{array}$ & 0.64 (0.30 to 1.38) & 0.62 (0.25 to 1.50$)$ & 0.40 (0.14 to 1.18$)$ & 0.59 (0.08 to 4.39$)$ \\
\hline $\begin{array}{l}\text { Age and time of sampling } \\
\text { adjusted odds ratio (95\% } \\
\text { Cl) comparing those with } \\
\text { clinical diagnosis of diabetes } \\
\text { to those without§ }\end{array}$ & 0.84 (0.61 to 1.14) & 1.02 (0.83 to 1.22$)$ & 0.88 (0.68 to 1.14) & 0.61 (0.16 to 2.38) \\
\hline
\end{tabular}

$\mathrm{GHQ}=$ general household questionnaire; $\mathrm{HOMA}=$ homoeostasis model assessment

${ }^{*}$ To calculate adjusted prevalence of high GHQ scores we used logistic regression models with the covariates age and time of blood sampling included as continuous variables centred around their mean values (that is, age in years minus mean age in years for the sample and time of sampling in 10 minute intervals minus mean time for the sample. Blood samples were taken between 8 am and $7 \mathrm{pm}$ ).

tOdds ratio of high GHQ per increase in one fourth of HOMA distribution among only those with no evidence (diagnosis or high fasting glucose $\geq 7.0 \mathrm{mmol} / \mathrm{l}$ ) of diabetes.

f0dds ratio comparing those with either a clinical diagnosis of diabetes or high fasting glucose $(\geq 7.0 \mathrm{mmol} / \mathrm{l})$ with all others.

$\S 0 d d s$ ratio comparing those with a clinical diagnosis of diabetes with all others (irrespective of fasting glucose level).

Our assessment of depression was based on GHQ rather than clinical assessment, and if insulin resistance is only protective against severe depression then this measure may be inadequate to detect an association. Also, any measurement error in our assessment of depression would tend to dilute the results. We validated the score, however, against a clinical interview in a subgroup. ${ }^{4}$

The contradictory results concerning the association of insulin resistance with depression and suicide warrant further research. Future studies might include trials of the effects on insulin resistance of treating depression. Observational studies should ideally use standardised diagnostic criteria for depression and prospectively assess the association of insulin resistance with differing severities.

\section{What is already known on this topic}

Cross sectional studies and those using indirect measurements indicate that insulin resistance may protect against depression

\section{What this study adds}

Insulin resistance was not associated with reduced depressive symptoms in a prospective study of middle aged men
The Caerphilly study was done by the former Medical Research Council Epidemiology Unit (South Wales) and was funded by the Medical Research Council of the United Kingdom. The department of social medicine, University of Bristol, is custodian for the Caerphilly database. We thank the men who participated in the study.

Contributors: YB-S, GDS, SE, and DAL developed the study idea. SAS validated the GHQ data. JY initiated the Caerphilly study, and YB-S, JEJG, and JWGY are responsible for the continued management of the study. DAL did the analysis and wrote the first draft of the paper, and all authors contributed to the final version. DAL and YB-S are guarantors.

Funding: DAL receives a UK Department of Health Career Scientist Award.

Competing interests: None declared.

Ethical approval: Phases I-III of the Caerphilly study were approved by Cardiff Local Research Ethics Committee and later phases by Gwent Research Ethics Committee.

1 Golomb BA, Tenkanen L, Alikoski T, Niskanen T, Manninen V, Huttunen $\mathrm{M}$, et al. Insulin sensitivity markers: predictors of accidents and suicides in Helsinki Heart Study screenees. J Clin Epidemiol 2002;55:767-73.

2 Lawlor DA, Davey Smith G, Ebrahim S. Association of insulin resistance with depression: cross sectional findings from the British women's heart with depression: cross sectional findings
and health study. BMJ 2003;327:1383-4.

3 Timonen M, Laakso M, Jokelainen J, Rajala U, Benno Meyer-Rochow V, Keinänen-Kiukaanniemi S. Insulin resistance and depression: cross sectional study. BMJ 2005;330:17-8.

4 Stansfeld SA, Gallacher JEJ, Sharp DS, Yarnell JWG. Social factors and minor psychiatric disorder in middle-aged men: a validation study and a population survey. Psychol Med 1991;21:157-67.

5 Matthews DR, Hosker JP, Rudenski AS, Naylor BA, Treacher DF, Turner RC. Homeostasis model assessment: insulin resistance and beta-cell function from fasting plasma glucose and insulin concentrations in man Diabetologia 1985;28:412-9.

(Accepted 10 January 2005)

doi 10.1136/bmj.38377.616921.F7 